\title{
APLIKASI TOTAL QUALITY MANGEMENT (TQM) PENDIDIKAN TINGGI DALAM RANGKA PELAYANAN PELANGGAN MAHASISWA ASING DI INTERNATIONAL ISLAMIC UNIVERSITY MALAYSIA (IIUM)
}

\begin{abstract}
Ahmad Hamid*
Abstract: This study aims to describe the role of Total Quality Management in order to increase foreign student customers. The method used is qualitative descriptive method. The selection of this method is to obtain an overall picture of the problem being studied. As for the unit of analysis or research subject as a source of data are the leaders, lecturers, staff, technical supervisors, and the students of International University of Malaysia (IIUM).The data was collected by using questionnaires. Interview method is used to support the research, and the obtained-data was analyzed through triangulation. In general, the results of this study show that continuously improvement and involve all elements of the organization starting from the rector of IIUM to personnel at the technical level in order to improve customer service quality of foreign students. This worked well and coordinated according to the system that has been applied and has been in accordance with international standards. Based on data analysis, it is known that in general, Total Quality Management (TQM) that is applied by the rector of the International Islamic University (IIUM) has reached an optimal point, whether it in terms of Customer Satisfaction, Continuous Improvement, Speaking with Fact, and Respect for People. Thus, it can be concluded that TQM applications in order to improve Customer Service Foreign Students at the International Islamic University Malaysia (IIUM) was a great influence in improving customer service quality of foreign students in accordance with the vision, mission and objectives of the International Islamic University Malaysia (IIUM)
\end{abstract}

Keywords: Total Quality Management, customer service.

\section{PENDAHULUAN}

Salah satu usaha lembaga pendidikan tinggi untuk meningkatkan kualitas sumber daya manusia (SDM) adalah dengan penerapan system Total Quality Management (TQM) yang merupakan suatu pendekatan dalam menjalankan usaha untuk memaksimumkan daya saing institusii melalui perbaikan terus menerus atas produk, jasa, manusia, proses dan lingkungannya. Agar pendidikan tinggi memiliki daya saing yang tinggi dalam skala global, maka harus mampu melakukan pekerjaan secara lebih baik, efektif dan efisien dalam menghasilkan lulusan yang berkualitas tinggi. pada masa mendatang bukan lagi mengandalkan keunggulan komparatif saja tetapi harus meningkatkan keunggulan kompetitif. Faktor-faktor Total Quality Management (TQM), terdiri dari empat komponen utama, yaitu: Riset pasar tenaga kerja, desain proses pendidikan tinggi, operasional proses pendidikan tinggi, dan penyerahan lulusan yang kompetitif dan berkualitas ke pasar tenaga kerja. Dalam hal ini diperlukan suatu interaksi tetap antara riset pasar tenaga kerja, desain proses pendidikan tinggi, operasional proses pendidikan tinggi, dan bertanggung jawab menghasilkan lulusan yang kompetitif dan berkualitas ke pasar tenaga kerja. Sedangkan ISO 9001-2000 adalah faktor penentu atas jaminan kualitas kelembagaan yang telah mendapat menggunakan sertifikasi mutu layanan internasional atau pengakuan standar manajemen internasional. Sistem inilah yang diterapkan oleh lembaga pendidikan tinggi di Malaysia diantaranya Universitas Islam Internasional Malaysia (UIIM) yang menggunakan standar mutu layanan internasional (sertifikat

\footnotetext{
* Pendiri Sekolah Tinggi Ilmu Tarbiyah (STIT) Pemalang
} 
ISO 9001-2000). International Islamic University Malaysia (IIUM) adalah Universitas swasta yang digagas pada tahun 1982, oleh Perdana Menteri Malaysia Dr. Mahatir Muhammad bekerjasama dengan Organisasi Konvensi Islam (OKI), dan di resmikan pada tanggal 10 Mei 1987. Deputi Mahathir, Anwar Ibrahim saat itu adalah sebagai rektor universitas Islam Internasional Malaysia (UIIM), Universitas ini sendiri mempunyai 14 fakultas, dilengkapi sarana dan prasarana yang moderen, dengan tujuan membangun Lembaga Pendidikan Tinggi Islam bertaraf Internasional yang di dasari pada prinsip-prinsip Islam (pengetahuan keIslaman), ilmu pengetahuan dan teknologi. International Islamic University Malaysia (IIUM) adalah Universitas yang unik di Malaysia karena memadukan kemoderenan dan disiplin profesional dengan nilai-nilai tradisonal serta sifat moral yang baik, dan mahasiswanya berasal lebih dari 120 negara. Penerapan Total Quality Manajemen (TQM), telah banyak memberikan dampak positif terhadap citra, international Islamic University Malaysia (UIIM), sehingga hampir seluruh perguruan tinggi di kawasan Asia merekomendasikan mahasiswa untuk melakukan studi di Universitas ini. Dari penjelasan diatas dapat terlihat bahwa pemerintah Malaysia telah melakukan kerja keras untuk mengembangkan pendidikan tinggi di berbagai Negara bagian serta berusaha meningkatkan kualitas pendidikan melalui kualitas pelayanan mahasiswa asing. Dengan gambaran diatas maka peneliti merasa tertarik untuk melakukan penelitian di International Islamic University Malaysia (IIUM) dengan judul "Aplikasi Total Quality Management (TQM) Pendidikan Tinggi dalam rangka Pelayanan Pelanggan Mahasiswa Asing di International Islamic University Malaysia (IIUM)

\section{Total Quality Management.}

Chang Zeph Yun Yeong Wee yong dan Lawrence Loh (1998:2) mendefinisikan bahwa: Total Quality Management (TQM), adalah pendekatan manajemen sebuah organisasi, yang berpusat pada mutu, berdasarkan pada partisipasi semua anggotanya dan bertujuan sukses jangka panjang melelui keputusan pelanggan, serta keuntungan bagi anggota organisasi dan masyarakat. Dalam Buku Total Quality Management in Government Cohen (1996:209) berpendapat TQM sebagai berikut : (1).Total menunjukkan pengertian mutu untuk setiap aspek kerja, mulai dari mengidentifikasi apakah pelanggan itu puas .(2). Quality berarti memenuhi dan melempui harapan pelanggan.(3). Management berarti mengembangkan dan memelihara kemampuan organisasi untuk terus-menerus meningkatkan mutu 8402 (Quality Vocabulary) mendefinisikan Total Quality Management (TQM), sebagai semua aktivitas dari fungsi menejemen secara keseluruhan yang menentukan kebijaksanaan kualitas, tujuan-tujuan dan tanggung jawab, serta mengimplementasikannya melalui alat-alat seperti (1). Perencanaan kualitas (qulity Plenning), (2). Pengendalian kualitas (Quality Control),(3). Jaminan kualitas (Quality Assurance), dan (4). peningkatan kualitas (Quality Improvement). Prinsip utama, Total Quality Management (TQM) adalah suatu pendekatan dalam menjalankan usaha untuk mencoba memaksimalkan daya saing organisasi melalui perbaikan terusmenerus atas produk jasa, manusia, proses dan lingkungannya. Karena itu, selanjutnya bahwa Total Quality Management (TQM) memiliki empat prinsip utama : 1) kepuasan pelanggan 2) respek terhadap setiap orang 3) manejemen berdasarkan fakta, 4) perbaikan berkesinambungan (Peter:1996:209).

Adapun yang menyangkut unsur-unsur Total Quality Manajement (TQM) menurut Joseph M. Juran yang dikutip Creech (1996:70) adalah meliputi; a) kualitas menjadi bagian dari setiap agenda manajemen atas b) sasaran kualitas 
dimasukkan dalam rencana bisnis. c) jangkauan sasaran diturunkan dari benchmarking, fokus adalah pada pelanggan dan pada kesesuaian kompetisi, di sana adalah sasaran untuk peningkatan kualitas tahunan. d) sasaran disebarkan ketingkat yang mengambil tindakan. e) pelatihan dilaksanakan pada semua tingkat. f ) pengukuran ditetapkan seluruhnya. g ) manajer atas sedar teratur meninjau kembali kemajuan dibandingkan dengan sasaran. $h$ enghargaan diberikan untuk performansi terbaik. i) Sistem imbalan (reward system) diperbaiki. Dengan demikian dari beberapa pendapat para ahli diatas, dapat di simpulkan tentang Total Quality Management (TQM), bahwa setiap keputusan dan tindakan yang dilakukan melalui perbaikan kesinambungan, adalah untuk memenuhi atau bahkan melebihi apa yang dibutuhkan (needs), dan yang diharapkan dan diinginkan (desire), oleh pelanggan. Total Quality Management (TQM) Pendidikan Tinggi diharapkan mampu menghilangkan atau mengurangi tingkat kesenjangan yang ada antara perguruan tinggi dan industri. Penerapan TQM Pendidikan Tinggi pada perguruan tinggi harus dijalankan atas dasar pengertian dan tanggung jawab bersama untuk mengutamakan efisiensi pendidikan tinggi dan peningkatan kualitas dari proses pendidikan tinggi. Bersamaan itu, pendidikan tinggi harus mampu memberikan hasil pruduk yang berkualitas. Produk pendidikan tinggi utamanya berbentuk jasa.

Kualitas jasa pendidikan tinggi memiliki beberapa sifat atau karakteristik antara lain; 1) subyektif, 2) umumnya berukuran afektif, 3) mengutamakan kepemerhatian, 4) terdiri dari nonmateri bisa berupa reputasi, sikap, tata krama, dan lain-lain, 5) tidak dapat dihitung secara kuantitatif, tetapi hanya bisa diyakini, dipercayai dan sebagainya, menejemen Pendidikan tinggi seyogianya memahami pula perkembangan manajemen sistem industri modern, sehingga mampu mendesain, menerapkan, mengendalikan, dan meningkatkan kinerja sistem pendidikan tinggi untuk memenuhi kebutuhan menejemen sistem industri modern. Hal ini dimaksudkan agar setiap lulusan dari pendidikan tinggi mampu dan cepat beradaptasi dengan kebutuhan sistem industri modern. Kondisi suatu negara dimasa akan datang, sebenarnya dapat diukur dari bagaimana wajah pendidikan tingginya saat ini. Karena tidak akan mungkin kita berharap kepada orang-orang yang tidak berpendidikan tinggi mengelola sebuah perubahan ke arah kemajuan bangsa, tetapi tentunya berharap pada orang-orang yang telah ditempa dalam sebuah laboratorium pendidikan (Perguruan Tinggi) dan memiliki karakter pembaharu, berbudaya intelektual.

Berkaitan dengan hal ini, sudah saatnya perguruan tinggi melakukan reorientasi dan redefinisi tujuan dari pendidikan tinggi, bukan sekedar menghasilkan lulusan sebanyak-banyaknya tanpa peduli akan kepuasan pengguna lulusan itu, melainkan juga harus bertanggung jawab untuk menghasilkan output (lulusan) yang kompetitif dan berkualitas agar memuaskan kebutuhan pengguna tenaga kerja terampil berpendidikan tinggi. Konsekuensi dari pemikiran ini adalah penerapan Total Quality Management (TQM) pada perguruan tinggi harus dijalankan atas dasar pengertian dan tanggung jawab bersama untuk mengutamakan efisiensi pendidikan tinggi dan peningkatan kualitas dari proses pendidikan tinggi itu. Melalui penerapan Total Quality Management (TQM) dalam sistem pendidikan tinggi yang dijalankan secara konsisten, maka perguruan tinggi akan mampu memenangkan persaingan global yang amat sangat kompetitif dan memperoleh manfaat (ekonomis maupun nonekonomis) yang dapat dipergunakan untuk pengembangan perguruan tinggi itu dan peningkatan kesejahteraan pegawai yang terlibat di perguruan tinggi itu. 
Dari uraian dan teori Total Quality Management (TQM) di atas, dapat ditarik kesimpulan bahwa Total Quality Management (TQM) adalah merupakan suatu pendekatan dalam menjalankan usaha di bidang jasa pendidikan khususnya pendidikan tinggi yang mencoba untuk memaksimalkan daya saing organisasi melalui perbaikan terus-menerus bagi kepuasan pelanggan,yang ditandai dengan indikator : (1) Customer Satisfaction, (2) Continuous Improvement (3) Speaking with Facts dan (4) Respect for people.

Pelayanan Pelanggan (Customer Service).

Pelanggan merupakan fondasi bisnis dan merekalah yang membuat bisnis tetap ada. Sebagaimana gambar di bawah ini :
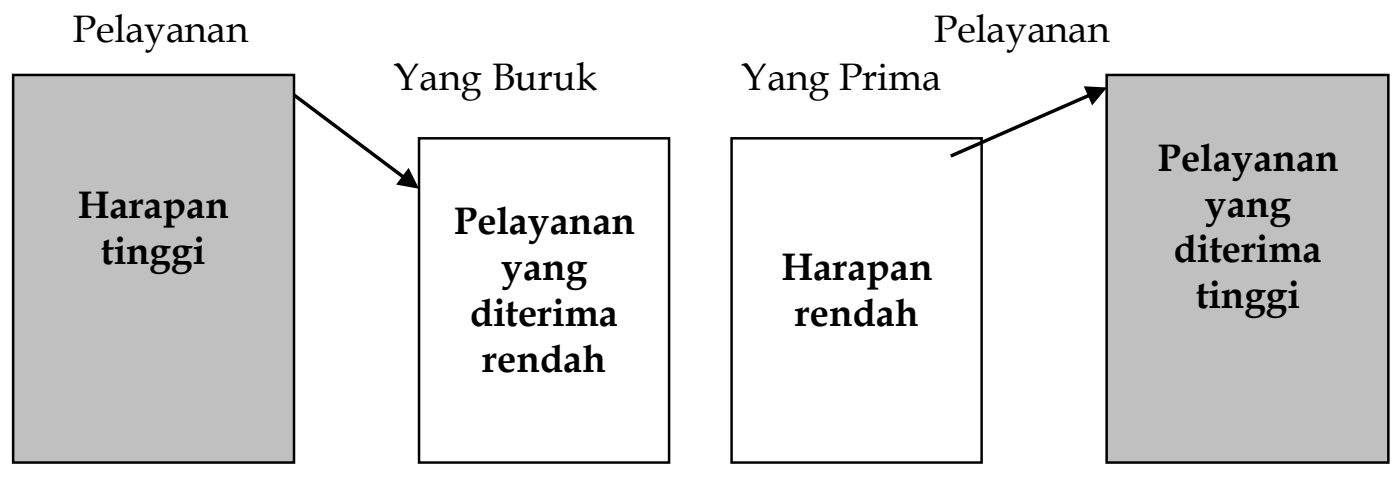

Gambar. 1. Melebihi Harapan

Sumber data : Sarah Cook Customer care Excellence

Dari gambar di atas dapat dipahami bahwa persepsi atas pelayanan dan harapan yang diterima oleh pelanggan tergantung pada harapan-harapan mereka. Jika perlakuan yang diterima pelanggan baik ketimbang yang diharapkan maka hal tersebut dianggap merupakan yang bermutu tinggi. Jika perlakuan diterima pelanggan kurang diharapkannya maka akan disebut sebagai pelanggan yang buruk. Untuk memberikan pelayanan yang bermutu tinggi, sebuah organisasi harus memberikan sesuatu yang melebihi apa yang diharapkan pelanggan. Menurut Payne (1993:220), "Service quality is concerned with the ability of an organization to meet or exceed customer expectactions". (Kualitas pelayanan adalah perhatian dengan segala kemampuan organisasi untuk memenuhi atau melebihi keinginan pelanggan). Kualitas pelayanan memerlukan suatu perhatian yang penuh dan baik serta dengan memberdayakan kemampuan suatu organisasi untuk mendapatkan pengetahuan mengenai apa yang dibutuhkan pelanggan bahkan melebihi dari harapan pelanggan. Menurut Kotler (1994:463) "Service quality is harder to define and judge than product quality. Customers will make judgements about service quality, and service providers need to know customer expectation in order to design effective service". (Pelayanan berkualitas sulit didefinisikan dan dinilai dari kualitas

produk. Para pelanggan akan menilai tentang pelayanan berkualitas dan pemberi pelayanan harus mengetahui keinginan pelanggan dengan mendesain pelayanan yang efektif). Zeithaml, Parasuraman, dan Berry telah melakukan berbagai penelitian terhadap beberapa jenis layanan, dan berhasil mengidentifikasi 5 (lima) dimensi karakteristik yang digunakan oleh para pelanggan dalam 
mengevaluasi mutu pelayanan. Kelima dimensi karakteristik mutu pelayanan tersebut adalah: (1) Reliability (kehandalan), yaitu kemampuan dan kehandalan dalam menyediakan pelayanan yang segera dan memuaskan serta sesuai dengan yang telah dijanjikan; (2) Responsiveness (daya tanggap), yaitu keinginan karyawan untuk membantu dan menyediakan pelayanan secara cepat dan tepat, serta tanggap terhadap keinginan pelanggan; (3) Assurance (jaminan), yaitu mencakup pengetahuan, keterampilan dan kemampuan serta kesopanan karyawan dalam memberikan layanan, aman dari bahaya, risiko, keraguan dan memiliki sifat dapat dipercaya; (4) Empathy (empati), yaitu meliputi kemudahan dalam berinteraksi, komunikasi yang baik, dan perhatian dengan tulus dan memahami kebutuhan dan keinginan pelanggan; (5) Tangibles (bukti fisik), yaitu meliputi fasilitas fisik, perlengkapan, karyawan dan sarana komunikasi.

Lima dimensi yang dikemukakan oleh Zeithaml di atas merupakan indikator atau ukuran yang digunakan dalam menentukan seberapa besar tingkat mutu pelayanan. Ini juga sama dengan apa yang dikemukakan oleh Kotler (1994:463) yaitu: (a) Kehandalan meliputi ketepatan waktu penyelesaian perizinan, pelayanan yang ramah serta selalu siap menolong. (b) Keresponsifan meliputi kemampuan organisasi untuk cepat tanggap dalam menghadapi masalah yang timbul, kemampuan organisasi cepat tanggap terhadap keluhan yang disampaikan pemohon. (c) Keyakinan meliputi pengetahuan dan kemampuan karyawan, melakukan komunikasi yang efektif dengan pemohon. (d) Empati meliputi memberikan perhatian secara individu kepada pemohon, bertanggung jawab terhadap keamanan dan kenyamanan pemohon. (e) Berwujud meliputi kebersihan dan kerapihan tempat pelayanan, penataan eksterior dan interior tempat ruang kerja.

Dari uraian di atas dapat disimpulkan bahwa pelayanan pelanggan adalah penyediaan tenaga kerja untuk meningkatkan sumber daya manusia, manfaat, harapan, kualitas, kepuasan, mempunyai jangka waktu panjang yang diterima oleh pelanggan sebagai akibat dari adanya pembelian yang dilakukan dan dari proses yang menuju tercapainya tujuan. Adapun indikatornya adalah : (1) Memahami kebutuhan (emphaty); (2) bukti langsung (tangible); (3) bebas resiko (assurance); (4) Kemampuan memberikan layanan (reliability); (5) Daya tanggap untuk membantu (responsiveness).

\section{Total Quality Management dalam Meningkatkan Pelayanan Pelanggan.}

Dalam kaitan Total Quality Management (TQM), Pendidikan tinggi sebagai institusi jasa pendidikan tinggi memposisikan dirinya yang maksimal dalam memberikan pelayanan (service) sesuai dengan apa yang diinginkan oleh pelanggan (Customer). Jasa atau pelayanan yang diinginkan oleh pelanggan tentu saja merupakan sesuatu yang berkulitas dan memberikan kepuasan kepada mahasiswa sebagai pelanggan. Maka pada saat itulah dibutuhkan suatu sistem menejemen yang mampu memberdayakan institusi pendidikan tinggi agar lebih berkualitas. Berdasarkan pada Implementasi unsur-unsur Total Quality Management (TQM) dapat diartikan sebagai suatu pendekatan dalam menjalankan usaha di bidang pelayanan jasa pendidikan tinggi yang mencoba untuk memaksimalkan daya saing organisasi melalui perbaikan terus-menerus. Menurut West-Burnham, menyatakan bahwa unsur-unsur Total Quality Management (TQM) Pendidikan tinggi yaitu terdiri dari empat 1) Prinsip-prinsip 2) Proses 3) pencegahan 4) manusia (Tjiptono:2003:37). Menurut Sallis, bahwa organisasi-organisasi yang menganut konsep Total Quality 
Management(TQM) melihat kualitas sebagai sesuatu yang diartikan oleh pelanggan, bahwa pelanggan adalah wasit terhadap mutu dan institusi itu sendiri tidak akan mampu bertahan tanpa mereka, Institusi pelaku Total Quality Management (TQM) harus menggunakan semua cara untuk mengekplorasi kebutuhan pelanggannya. Pelayanan pelanggan merupakan salah satu penghubung aktivitas dalam manajemen mutu terpadu. Pelayanan pelanggan adalah penghubung pertama dalam rantai aktivitas untuk manajemen mutu terpadu yang akan datang pada tingkat yang lebih tinggi (Harrington:1993:15).

\section{METODE}

Metode yang digunakan dalam penelitian ini adalah metode kualitatif. Penelitian ini dilaksanakan di Universitas Islam Internasional Malaysia (UIIM) yang berada di Gombak Selangor Malaysia. Sedangkan waktu pelaksanaan penelitian mulai bulan Maret sampai dengan bulan Mei 2009. Unit analisis dalam penelitian ini adalah: Rektor, Deputy Rektor dan Dekan (3 orang untuk wawancara), Mahasiswa asing (5 orang untuk wawancara), Direktur Devision, dosen, karyawan (40 orang untuk kuesioner), Mahasiswa asing (40 orang untuk kuesioner).

\section{HASIL DAN PEMBAHASAN}

Total Quality Management (TQM)

Kepuasan Pelanggan (Customer Satisfaction).

Kualitas pelayanan yang dilakukan oleh pimpinan IIUM sama dengan nilai (value) yang diberikan dalam rangka meningkatkan kualitas hidup para pelanggan internal, semakin tinggi nilai yang diberikan kepada pelanggan internal maka semakin besar pula kepuasan pelayanan pelanggan yang diberikan kepada kepuasan pelayanan ekternal dalam hal ini mahasiswa asing di IIUM. Untuk itu ketika nilai (value), sudah diberikan oleh rektor IIUM, kepada pelanggan internal (staf karayawan/pegawai, dosen, petugas teknis) maka harus di ikuti dengan tingkat pelayanan yang memuaskan seperti hal nya keamanan mahasiswa asing didalam maupun ketika berada diluar kampus dan menjaga kenyaman suasama didalam proses belajar, kenyaman suasana di asrama putra - putri, sarana olah raga, kenyamanan suasana dalam pelayanan pembayaran SPP, pengurusan perpanjang visa, tidak berbelit dan cepat foto copi, Kantin mahasiswa, toko buku, klinik, perpustakaan dan lebih khusus adalah penciptaan suasana Masjid.

\section{Respek Terhadap Setiap Orang (Respect for People)}

Setiap karyawan dipandang sebagai individu yang memiliki kreativitas tersendiri. Dengan demikian karyawan merupakan sumber daya organisasi yang peling bernilai. Oleh karena itu pimpinan IIUM, harus selalu memberikan perlakuan dengan baik dan memberikan kesempatan untuk terlibat dan berpartisipasi dalam tim pengambil keputusan. Oleh sebab itu keterlibatan semua

unsur terutama pimpianan dan respek terhadap setiap orang terutama, terhadap pelayanan pelanggan mahasiswa asing, untuk itu pimpinan (rector) IIUM harus selalu memberikan pengarahan atau pelatihan tentang cara menghargai dan menghormati pelanggan, sehingga pelanggan tersebut merasa nyaman dan 
memberikan penjelasan tentang tata cara menerima telepon dan menyabut tamu dengan sikap simpati dan bertanggung jawab.

\section{Manajemen berdasarkan fakta (Speaking With Facts)}

Setiap keputusan selalu didasarkan pada data, bukan sekedar pada perasaan (feeling). Ada dua konsep pokok berkaitan yaitu : (1) prioritisasi (prioritization) yakni suatu konsep bahwa perbaikan tidak dapat dilakukan pada semua aspek pada saat yang bersamaan, mengingat keterbatasan sumber data yang ada. dengan menggunkan data maka manajemen dan tim dalam organisasi dapat memfokuskan usahanya pada situasi tertentu yang vital,(2) variasi (variation) atau variabilitas kinerja manusia. Betapa pentingnya data sebagai bahan dalam pengambilan keputusan. Oleh sebab itu keterlibatan unsur pimpinan dan seluruh karyawan dalam pengambilan keputusan yang berdasarkan pada fakta dapat memberikan prediksi hasil dari setiap keputusan dan tindakan yang dilakukan demi mencapai tujuan organisasi yang baik. Setiap keputusan atau kebijakan yang dilakukan oleh Pimpinan (rektor) International Islamic University Malaysia (IIUM) selalu berdasarka pada fakta data-data, yang di peroleh dari berbagai fakultas dan divisi yang ada dalam IIUM, untuk itu setiap fakta data harus di arsipkan atau simpan dengan baik sebagai laporan kepada pimpinan sebagai bahan pengambilan keputusan, kebijakan dan sebagai bahan evaluasi.

\section{Perbaikan berkesinambungan (Continuous Improvement)}

Agar dapat sukses, setiap organisasi perlu melakukan proses secara sistematis dalam melakukan perbaikan berkesinambungan. Konsep yang berlaku disini adalah siklus PDCA (plan-do-chek-act), yang terdiri dari langkah-langkah perencanaan, dan tindakan korektif terhadap hasil yang diperoleh (Wellinton:1998:37). Perbaikan berkesinambungan dengan menggunakan langkah-langkah perencanaan hal itu yang harus dilakukan oleh setiap pimpinan dan melibatkan semua unsur dalam organisasi sesuai dengan bidang tugasnya masing-masing. Oleh karena itu Pimpinan (rektor) International Islamic University Malaysia, dalam melakukan perbaikan berkesenambungan dalam setiap struktur organisasi harus mengikutsertakan komponen lain dalam lingkungan universitas seperti Deputi rektor, dekan fakultas, direktur divisi, dan dosen serta staf karyawan. Dengan demikian, agar visi - misi dan tujuan organisasi dalam hal ini International Islamic University Malaysia (IIUM) dapat tercapai dan tidak terjadi sesuatu kesalah fahaman dalam pengambilan keputusan.

\section{Pelayanan Pelanggan}

Memahami kebutuhan (emphaty)

Menurut Kotler dalam Saroya mutu pelayanan pelanggan harus dimulai dari kebutuhan pelanggan dan berakhir pada persepsi mereka. Dengan memahami apa yang menjadi kebutuhan pelanggan maka kita akan mengetahui apa yang menjadi persepsi pelanggan. Hal ini berarti bahwa citra mutu pelayanan yang baik bukanlah berdasarkan sudut pandang atau persepsi pihak penyedia layanan, melainkan berdasarkan sudut pandang atau persepsi pelanggan. Pelangganlah yang mengkonsumsi dan menikmati layanan, sehingga merekalah yang seharusnya menentukan mutu pelayanan. Berdasarkan hasil temuan peneliti di lapangan yaitu di UIIM, dapat dipastikan bahwa pihak penyedia layanan dalam hal ini adalah International Islamic University Malaysia sangat memahami kebutuhan pelanggannya yaitu para 
mahasiswa asing maupun yang lokal. Hal tersebut terlihat dari hubungan baik yang terjalin antara mahasiswa dan dosen serta pelayanan akademik yang selalu dapat melayani mahasiswa dengan berbagai keluhannya.

\section{Tangibles (Bukti langsung)}

Berdasarkan hasil temuan penelitian diketahui bahwa kampus International Islamic University Malaysia (IIUM), telah menyediakan sarana yang mendukung proses pembelajaran yang meliputi : Gedung Perpustakaan, Laboratorium Pratikum, laboratorium komputer di setiap fakultas, masjid, klinik 24 jam, kantin cita rasa 120 negara yang digabungkan menjadi empat cita rasa (Asia, Eropa, Afrika, dan Amerika), Internet, telepon di setiap sudut asrama putra-putri dan sarana olah raga dan fasilitas santai yang memadai bagi semua mahasiswa asing.

Dari penjelasan tersebut di atas maka dalam penerapan Total Quality Management (TQM), fokus terhadap pelayanan pelanggan dengan memberikan kenyamanan dan ketenangan. Untuk itu keterlibatan Staf karyawan atau pegawai yang dituntut dan harus memiliki sifat yang baik, santun, disiplin, memiliki etos kerja tinggi dan menguasai dan memahami visi-misi tujuan IIUM. Dengan demikian maka Pimpinan atau rektor UIIM, harus sering memberikan pengarahan, motivasi bahwa bekerja adalah ibadah kepada Allah SWT, dan penghargaan kepada pegawai atas sampai pada pegawai teknis di lapangan, hal ini agar menumbuhkan semangat memiliki bahwa bekerja untuk diri sendiri dan kepentingan dan kemajuan Islam.

\section{Assurance (jaminan)}

Assurance (jaminan) yaitu mencakup pengetahuan, keterampilan dan kemampuan serta kesopanan karyawan dalam memberikan layanan, aman dari bahaya, resiko, keraguan dan memiliki sifat dapat dipercaya. Menurut Rosenbluth dan Peters (1992:39), kenyamanan di tempat kerja merupakan kunci dalam menyediakan atau memberikan layanan yang prima kepada para pelanggan. Oleh karena itu perlu diciptakan suatu lingkungan kerja dimana para karyawan hanya berfokus pada pelanggan atau klien semata. Lebih lanjut, Rosenbluth dan Peters menegaskan bahwa pekerjaan layanan itu dimulai dari dalam hati orang yang melayani. Untuk hal ini, organisasi perlu memberikan training kepada karyawannya hal-hal yang berkaitan dengan mutu pelayanan dalam menghadapi pelanggan. Berdasarkan hasil observasi peneliti di lapangan dan berdasar dari hasil temuan penelitian di UIIM, maka dapat diketahui bahwa indikator assurance (jaminan) telah terlaksana dengan baik. Hal ini terlihat dari pengoptimalan pelayanan mahasiswa asing sesuai dengan standar internasional dan adanya jaminan keamanan dan kesehatan untuk mahasiswa serta tersedianya pelayanan internet bagi seluruh mahasiswa selama jam pembelajaran berlangsung.

Reability (kehandalan)

Reliability (kehandalan), yaitu kemampuan dan kehandalan dalam menyediakan pelayanan yang segera dan memuaskan serta sesuai dengan yang telah dijanjikan. Menurut Payne (1993:220), "Service quality is concerned with the ability of an organization to meet or exceed customer expectactions". (Kualitas pelayanan adalah perhatian dengan segala kemampuan organisasi untuk memenuhi atau melebihi keinginan pelanggan). Kualitas pelayanan memerlukan suatu perhatian 
yang penuh dan baik serta dengan memberdayakan kemampuan suatu organisasi untuk mendapatkan pengetahuan mengenai apa yang dibutuhkan pelanggan bahkan melebihi dari harapan pelanggan.

Berdasarkan hasil pengamatan peneliti di lapangan dan berdasarkan dari hasil temuan penelitian di UIIM, maka dapat diketahui bahwa indikator reliability (kehandalan) telah dilakukan dengan baik oleh pihak universitas. Hal ini terlihat dari pelayanan yang telah disediakan oleh pihak Universitas Islam Malaysia. Tersedianya pelayanan pre-enty untuk semua mahasiswa asing dan adanya semua Jenis teknologi pembelajaran dalam rangka meningkatkan pelayanan pelanggan kepada mahasiswa asing. Serta pelayanan pembayaran SPP melalui bank, hal ini sangat memudahkan mahasiswa untuk melakukan pembayaran.

\section{Responsiveness}

Responsiveness (daya tanggap), yaitu keinginan karyawan untuk membantu dan menyediakan pelayanan secara cepat dan tepat, serta tanggap terhadap keinginan pelanggan. Keinginan para pegawai untuk membantu para pelanggan dan memberikan pelayanan pelanggan dengan tanggap dan dewasa ini telah banyak ditulis mengenai "learning organization", antara lain Peter Senge (1990) dari Massachusetts Institute of Technology (MIT). Sekarang, organisasi dimanapun mengalami tantangan untuk melakukan perubahan demi perbaikan. Dalam keadaan tersebut, Total Quality Management (TQM) dalam gerakannya mulai memasuki bidang bagian baru dalam perubahan tersebut, yaitu pendidikan tinggi. Sebagaimana organisasi industri, pendidikan tinggi juga memiliki, "customers", yang memiliki kemampuan dan keperdulian serta tanggap terhadap setiap peluang yang terjadi yaitu pemakai hasil didik.

Berdasarkan hasil pengamatan peneliti di lapangan dan berdasarkan dari hasil temuan penelitian di UIIM, maka dapat diketahui bahwa indikator responsiveness (daya tanggap) telah dilakukan dengan baik oleh pihak universitas. Hal ini terlihat dari pelayanan yang telah diberikan universitas kepada para pelanggannya yaitu mahasiswa.

\section{PENUTUP}

Kesimpulan. Berdasarkan hasil temuan peneliti, maka dapat disimpulkan bahwa International Islamic University Malaysia (IIUM) dalam mengaplikasikan Total Quality Management (TQM) untuk meningkatkan pelayanan pelanggan mahasiswa Asing secara umum sudah sangat optimal. Hal ini dapat dilihat dari jumlah nilai prosentasi yang di peroleh dari data pernyataan yang diberikan melalui kuesioner Total Quality Management dengan indikator: (1) Customer Satisfaction, ,(2) Continuous Improvement (3) Speaking with Facts dan (4) Respect for people. Untuk itu dalam TQM, konsep mengenai kualitas layanan pelanggan diperluas. Kualitas tidak lagi hanya bermakna kesesuian dengan spesipikasispesipikasi tertentu, tetapi kualitas tersebut ditentukan oleh pelanggan. Sementara itu untuk pelayanan pelanggan juga diketahui bahwa pelayanan pelanggan karyawan tergolong sangat tinggi, baik dimensi reliability, responsiveness, assurance, empathy maupun tangibles. Hal ini terlihat dari semua indikator dalam variabel pelayanan pelanggan dalam analisis prosentase yang terkategori sangat tinggi. Sedangkan dari hasil wawancara yang 
diperoleh, menunjukan kualitas pelayanan yang diberikan kepada pelanggan mahasiswa asing menunjukan sangat memuaskan dengan upaya-upaya yang dilakukan oleh pimpinan Universitas, staf pimpinan, dekan, direktur divisi, staf karayawan, dosen dan petugas tehnis sangat tepat dan lebih efektif. Hal tersebut terlihat dari data hasil wawancara kebanyakan menyatakan sangat setuju dan mendukung terhadap upaya program yang telah dilakukan pimpinan dalam rangka memberikan kualitas layanan yang nyaman dan damai dengan pencanangan "hari kualitas" dan pelaksanaan visi-misi bagi civitas akademika. Upaya-upaya yang dilakukan oleh International Islamic University Malaysia (IIUM), terlihat dari; (1) economi reward dan kenyamanan kerja serta kebijaksanaan (2) Instrinsic satisfaction (kepuasan dari dalam diri), yaitu berupa penghargaan keberhasilan dalam melaksanakan pekerjaan dan memperoleh tanggung jawab yang lebih besar, dan (3) social relationship (hubungan sosial), yaitu hubungan dengan staf dan kerjasama tim. Dari hasil penelitian di lapangan dapat dikatakan bahwa aplikasi Total Quality Manajement dapat meningkatkan pelayanan pelanggan khususnya bagi mahasiswa asing di International Islamic University Malaysia.

Saran. disarankan agar system manajemen International Islamic University Malaysia (IIUM), dapat dipertahankan dan ditingkatkan dengan lebih baik lagi , sebab dengan upaya-upaya yang dilakukannya saat ini dapat meningkatkan pelayanan pada semua sektor, namun dalam hal ini disarankan untuk lebih difokuskan pada aspek disiplin dan rekrutmen mahasiswa baru, kerena dari hasil penelitian diketahui bahwa ada sedikit penurunan jumlah penerimaan mahasiswa baru asing.pada tahun akademik 2009-2010. untuk itu disarankan agar anggaran promosi lebih ditingkatkan, , maksimalkan angkuatan bus bagi mahasiswa asing untuk bepergian pada hari-hari libur sehingga mahaiswa asing tidak merasa jenuh. Dengan demikian sebagai tindak lanjut dari hasil penelitian ini ada baiknya dilakukan penelitian lanjutan dengan pendekatan metode kuantitatif untuk mengetahui lebih jauh dan detail mengenai aplikasi total quality management pendidikan tinggi dalam rangka meningkatkan pelayanan pelanggan mahasiswa asing di International Islamic University Malaysia (IIUM). 


\section{DAFTAR RUJUKAN}

Creech, B. Lima pilar Manajemen Mutu Terpadu: Cara membuat Bekerja bagi anda, Alih bahasa: Sindoro. A. Jakarta, Binarupa Aksara,1996.

Hang Zeph Yun, The Quest For Global Quality singapore Airlines, Jakarta : Pustaka,1998.

J. H. Harrington and James S. Harrington. Total Improvement Management.. McGraw-Hill, Inc., New York, 1993.

Kotler, Philip, Marketing Management: Analysis, Planning, Implementation and Control. $8^{\text {th }}$ ed, Englewood Cliffs. New York: Prentice Hall, 1994.

Patricia, Wellington. Kaizen Strategies for Costumer Care. Batam : Interaksa, 1998

Payne, Adrian. The Essence of Services Marketing, New York; Prentice-Hall, 1993.

Peter Tom, Crazy Times For Crazy Organistions Jakarata, Delapratasa, 1994.

Rosenbluth, Hal F, Peters, Diane McFerrin., The Customer Comes Second and Other Secrets of Exceptional Service. New York: Quill, 1992.

Tjiptono, Fandy \& Anastasia Diana, Total Quality Management. Yogyakarta : Andi 2005. 